MASCARENHAS, Raquel Mota. Jovens pobres: considerações sobre os espaços de socialização. Oikos: Família e Sociedade em Debate, v. 29, n. 2, p. 330-349, 2018.

\section{PPGED}

Programa de Pós-Graduação

em Economia Doméstica

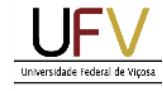

www.periodicos.ufv.br/oikos | ISSN: 2236-8493 revistaoikos@ufv.br
Avaliação: Double Blind Review Recebido: 12/08/2018 Aprovado: 10/11/2018

\title{
Jovens pobres: considerações sobre os espaços de socialização
}

\section{Poor young: considerations about socialization spaces}

Raquel Mota Mascarenhas ${ }^{1}$

\section{Resumo}

Este artigo, a partir de pesquisa bibliográfica, objetiva elencar algumas considerações acerca dos espaços de socialização no cotidiano das/dos jovens pobres. Considera que as esferas tradicionais de socialização - a família, a escola e o trabalho - apresentam situação de crise dimensional em relação às novas demandas das juventudes. Mediante isso, busca-se refletir acerca da esfera da produção cultural juvenil, como locus de socialização, a fim de contribuir para o entendimento das/dos jovens acerca da realidade social. Assim, busca-se ofertar subsídios para a formulação de políticas públicas e para a atuação profissional junto a esse público.

Palavras-Chave: Juventudes; Socialização; Produção cultural.

\begin{abstract}
This article, from bibliographic research, aims to build considerations about socialization spaces exist in daily lives of poor youths. Considers that traditional spheres human socialization - family, school and work - have a crisis situation dimensional in relation new demands of the youths. View this, seeks reflect on sphere youth cultural production as locus socialization. Aims contribute the understanding young about social reality, well presenting subsidies formulation public policies and professional action with public.
\end{abstract}

Keywords: Youths; Socialization; Cultural Production.

\footnotetext{
${ }^{1}$ Doutoranda em Serviço Social pela Universidade Federal do Rio de Janeiro (UFRJ). Mestre em Política Social pela Universidade Federal do Espírito Santo (UFES). Professora Assistente II da Universidade Federal de Ouro Preto (UFOP). E-mail: rmmascarenhas.ufop@gmail.com
} 


\section{INTRODUÇÃO}

Este artigo objetiva elencar algumas considerações acerca dos espaços de socialização no cotidiano das/dos jovens pobres na contemporaneidade. Para isso, reuniu-se aqui alguns elementos constitutivos desse universo, a fim de problematizar a visão hegemônica acerca dos sujeitos juvenis que, em situação de pobreza, habitam em territórios marcados pela desigualdade social, não obstante, costumeiramente retratados em manchetes de jornais como local de forte violência urbana, associada, principalmente, ao tráfico de drogas.

Tal contexto tornou a segurança pública, focalizada no policiamento militar, o elemento central da intervenção estatal voltada a esse segmento populacional. Enquanto as políticas sociais de educação, saúde, assistência social e cultura figuram de forma incipiente, quando não inexistentes (SOUZA, 1999; SPOSITO, CARRANO, 2003).

Almeja-se, portanto, contribuir com a atuação profissional na gestão e execução de políticas públicas com as/os jovens as quais estejam alinhadas à promoção do protagonismo desses sujeitos na construção de estratégias de lutas e vivências cotidianas. É sabido que tal norteamento profissional não consiste em tarefa fácil, mas possível, desde que haja competência teórico-metodológica, ético-política e técnico operativa, advinda de constante aperfeiçoamento.

Assim, de forma exploratória, a fim de "[...] proporcionar maior familiaridade com o problema, com vistas a torná-lo mais explícito [...]" (GIL, 2002, p. 41), apresenta-se a síntese da pesquisa bibliográfica ${ }^{2}$, mediante a utilização da leitura ${ }^{3}$, como técnica de coleta de dados. Isto é, a partir da identificação e caracterização das obras, elencou-se suas contribuições para o estudo proposto, cuja síntese integradora segue aqui apresentada (LIMA; MIOTO, 2007).

Para a ideação do objeto, os espaços de socialização das/dos jovens pobres, faz-se uso do método histórico dialético marxista, que articula três categorias nucleares para a sua concepção teórico-metodológica: totalidade, contradição e mediação. Desse modo, entende-se a realidade social como totalidade concreta de máxima complexidade, constituída por totalidades de menor complexidade. Essas totalidades, por sua vez, estão em movimento constante e contraditório em si e entre si, sendo articuladas por um sistema de mediações. Logo, sendo a realidade social historicamente mutável, o objeto constitui-se por infinitas determinações, das quais se visa uma aproximação sucessiva (MARX, 2011a; NETTO, 2011).

\footnotetext{
2 A pesquisa bibliográfica consiste em ser "[...] desenvolvida com base em material já elaborado, constituído principalmente de livros e artigos científico" (GIL, 2002, p. 44).

${ }^{3}$ No que tange à leitura, entende-se que "[...] é através dela que podemos identificar as informações e os dados contidos no material selecionado, bem como verificar as relações existentes entre eles de modo a analisar sua consistência" (LIMA; MIOTO, 2007, p. 41)
} 
Diante o exposto, a materialização da síntese integradora segue apresentada em três momentos, além dessa introdução: problematização do conceito de juventude inserida no processo de socialização; reflexão acerca dos espaços de socialização tradicional (a família, a escola e o trabalho) e a esfera da produção cultural; e, por fim, algumas considerações finais.

\section{JUVENTUDE OU JUVENTUDES?}

O conceito de juventude está imerso em amplo debate teórico, no qual sinalizamos para distinção entre dois eixos, que parte da contribuição de Pais (2010) e Dayrel (2010), mas se propõe ir além, pontuando alguns avanços para a reflexão da juventude pobre na contemporaneidade.

No primeiro eixo, denominado corrente geracional (PAIS, 2010), a juventude é entendida como a fase da vida, em que a/o jovem é caracterizada/o como tal pela idade que possui e pelo padrão de comportamento. Essa, hegemônica no cenário contemporâneo, infere na formalização legal do intervalo de idade, principalmente, objetivando o recorte populacional para fins estatísticos. Acerca disso, a Organização das Nações Unidas (ONU), pela primeira vez, em 1985, definiu como jovens as pessoas entre os 15 e os 24 anos, entretanto, sem prejuízo de outras definições de Estados membros. Como exemplo, o Brasil, no Estatuto da Juventude ${ }^{4}$, que considera jovens as pessoas com idade entre 15 e 29 anos de idade, logo, demonstra a ampliação de recorte (BRASIL, 2013). Além do marco cronológico, a tipificação do comportamento caracteriza a corrente geracional, que se expressa nas imagens da juventude como fase transitória, cujo objetivo central é ser o momento de preparação para a vida adulta; fase de liberdade, na qual se poderia ter comportamentos exóticos e irresponsáveis, autorizados por um tipo de moratória social; fase de crise, caracterizada por conflitos familiares e psicológicos. Acerca dessa, Pais (2010, p. 152), esclarece que:

A corrente geracional toma como ponto de partida a noção de juventude quando referida
a uma fase de vida, e enfatiza, por conseguinte, o aspecto unitário da juventude. [...] A
questão essencial a discutir no âmbito desta corrente diz respeito à
continuidade/descontinuidade dos valores intergeracionais. O quadro teórico dominante
baseia-se nas teorias da socialização desenvolvidas pelo funcionalismo e na teoria das
gerações. Problematizando essa abordagem, concordamos com Dayrell (2003) quando afirma que:

${ }^{4}$ O Estatuto da Juventude brasileiro foi instituído pela Lei n. 12.852, de cinco de agosto de dois mil e treze, o qual dispõe sobre os direitos dos jovens, os princípios e diretrizes das políticas públicas de juventude e o Sistema Nacional de Juventude (SINAJUVE) (BRASIL, 2013). 
Torna-se necessário colocar em questão essas imagens, pois, quando arraigados nesses "modelos" socialmente construídos, corremos o risco de anali-sar os jovens de forma negativa, enfatizando as características que lhes faltariam para corresponder a um determinado modelo de "ser jovem". Dessa forma, não conseguimos apreender os modos pelos quais os jovens, principalmente se forem das camadas populares, constroem as suas experiências.

Diante disso, o segundo eixo, denominado corrente classista (PAIS, 2010), compreende a juventude como o grupo populacional cuja socialização é determinada pela classe social em que está alocada/o, isto é, considera que as culturas juvenis seriam sempre culturas de classe, produto das relações sociais antagônicas. Nessa abordagem, Pais (2010, p. 157), esclarece que:

\begin{abstract}
Com efeito, enquanto, para a corrente geracional, a reprodução se restringe à análise das relações intergeracionais, isto é, à análise da conservação ou sedimentação (ou não) das formas e conteúdos das relações sociais entre gerações, para a corrente classista, a reprodução social é fundamentalmente vista em termos da reprodução das classes sociais.
\end{abstract}

Diante da delimitação dessas duas correntes, propostas por Pais (2010), considera-se que a classista, sem negar as contribuições da geracional, contribui para ampliação da análise acerca da juventude na contemporaneidade; e, assim, destaca a impossibilidade de conceituar a "juventude" como um bloco monolítico e uniforme, apenas delimitado de forma cronológica e comportamental - como sinaliza a primeira. Portanto, observando o método marxista histórico dialético, este trabalho se alinha à segunda corrente e busca elencar, a partir da pesquisa bibliográfica, algumas contribuições teóricas que contribuem para o adensamento dessa abordagem acerca da juventude.

Nesse sentido, não se considera, como afirma Pais (2010), que a corrente classista pressupõe abordagem determinista da juventude, mas que inova no entendimento de que a/o jovem é um sujeito ativo na construção das relações sociais que experiencia. Desse modo, ratifica-se o exposto por Dayrell (2003, p. 42) quando afirma que:

\begin{abstract}
A juventude constitui um momento determinado, mas não se reduz a uma passagem; ela assume uma importância em si mesma. Todo esse processo é influenciado pelo meio social concreto no qual se desenvolve e pela qualidade das trocas que este proporciona. Assim, os jovens [...] constroem determinados modos de ser jovem que apresentam especificidades, o que não significa, porém, que haja um único modo de ser jovem nas camadas populares. É nesse sentido que enfatizamos a noção de juventudes, no plural, para enfatizar a diversidade de modos de ser jovem existentes. Assim compreendida, torna-se necessário articular a noção de juventude à de sujeito social.
\end{abstract}

Portanto, a fim de refletir acerca dos espaços de socialização no cotidiano das/dos jovens pobres, parte-se do entendimento de que esses espaços estão imersos no desenvolvimento intensivo e extensivo do capitalismo, que gera desigualdades - como o aprofundamento e a 
generalização da pobreza - bem como, os antagonismos entre classes - expressos nos conflitos sociais entre trabalhadores e burguesia, que permeia os espaços de convivência coletiva, gerando, por vez, a criminalização dos pobres. O que indica o tensionamento próprio da "questão social". Ou seja, como afirma Netto (2009, p. 32).

[...] tomar a "questão social" como problemática configuradora de uma totalidade processual específica é remetê-la concretamente à relação capital/trabalho - o que significa, liminarmente, colocar em xeque a ordem burguesa. [...] as sequelas da "questão social" são recortadas como problemáticas particulares (o desemprego, a fome, a carência habitacional, $o$ acidente de trabalho, a falta de escolas, a incapacidade física etc.).

Logo, a conjuntura social de construção da socialização das/dos jovens é entrecortada pelas condições estruturais que estabelecem uma gama de vivências possíveis e outras improváveis, que delineiam o seu acesso (ou não) a determinados serviços e bens materiais e imateriais, alcances próprios de sua classe social. Essa estrutura social origina-se da lei geral de acumulação capitalista, como expõe Marx (2011b, p. 748):

Graças ao progresso da produtividade do trabalho social, quantidade sempre crescente dos meios de produção pode ser mobilizada com o dispêndio progressivamente menor de força humana. Esse enunciado é uma lei da sociedade capitalista [...]. Quanto maior a produtividade do trabalho tanto maior a pressão dos trabalhadores sobre os meios de emprego, tanto mais precárias suas condições de existência [...]. O capitalismo determina uma acumulação de riqueza num polo e ao mesmo tempo acumulação de miséria, de trabalho atormentante, escravatura, ignorância, brutalidade e degradação moral no polo oposto, constituído pela classe cujo produto vira capital.

Entende-se, desse modo, que a pobreza trata-se de expressão da "questão social", cuja gênese está situada na lei geral de acumulação capitalista, que expressa a relação direta entre a produção de riqueza e pobreza desse modo de produção. Desse modo, é necessário compreender a pobreza como fenômeno que possui dimensão histórica e material, como afirma Silva (2010, p. 157):

[...] o entendimento é de que o sistema de produção capitalista, centrado na expropriação e na exploração para garantir a mais valia e a repartição injusta e desigual da renda nacional entre as classes sociais são responsáveis pela instituição de um processo excludente, gerador e reprodutor da pobreza, entendida enquanto fenômeno estrutural, complexo, de natureza multidimensional, relativo, não podendo ser considerada como mera insuficiência de renda.

No entanto, sem depreciar essa dimensão de análise da totalidade, Sarti (2005) afirma ser necessário que, ao se referir aos sujeitos em situação de pobreza, busque-se ir para além do "pressuposto da falta", ponderando a sua "positividade concreta". Isto é, não se deve considerar os pobres apenas, ou pior, exclusivamente, a partir da referência da falta, pois esses não são 
sujeitos passivos, eles agem sobre o mundo e pensam sobre esse agir. Portanto, ao não observar esses elementos, como expõe a autora:

[...] o resultado acaba sendo a desatenção para a vida social e simbólica dos pobres no que ela representa como positividade concreta, a partir da qual se define o horizonte de sua atuação no mundo social e a possibilidade de transposição dessa atuação para o plano propriamente político (SARTI, 2005, p. 36).

Logo, não se trata de questão secundária, uma vez que impacta o planejamento e a prática social dos profissionais da área. Desse modo, como afirma Leite (2008, p. 93), ao restringir os pobres pelo viés do "pressuposto da falta", "[...] tais profissionais estarão caminhando a passos largos para o assistencialismo. Buscarão ajudar aqueles que são vistos como fracos e impotentes diante da realidade"; e assim "[...] Procurarão propiciar-lhes auxílio, mas não formular estratégias e desenvolver ações práticas que possam contribuir para que conquistem direitos".

Portanto, conclui-se que as "juventudes" tomam contornos distintos de acordo com as experiências vivenciadas pelas/pelos jovens em seu contexto social. Essas são determinadas pelo pertencimento à distinta classe social - trabalhadores ou burguesia - e mediadas por um conjunto de particularidades, como a situação de pobreza ${ }^{5}$. Diante dessa compreensão de realidade social, tem-se que "ao lado da sua condição como jovens, alia-se a da pobreza, numa dupla condição que interfere diretamente na trajetória de vida e nas possibilidades e sentidos que assumem a vivência juvenil" (DAYRELL, 2007, p. 1108-1109). Ou seja, entender a juventude, como uma fase temporal no curso da vida, não significa compreendê-la de forma linear e evolutiva, visto que ela baliza cada ser humano de forma diferenciada, de acordo com as experimentações de seu lugar no mundo enquanto jovem.

\section{SOCIALIZAÇÃO E JUVENTUDE POBRE}

Ao se pensar em jovem, ou seja, no que é ser um humano jovem, consequentemente, pensar-se-á no que é ser humano.

Sabe-se das diferentes teorizações sociais existentes para explicar o processo de humanização, no entanto, compreende-se que não basta o pertencimento ao gênero humano, em particular à espécie homo sapiens, para concretizar-se em um ser social. Esse elemento consiste na dimensão natural humana, em que:

\footnotetext{
${ }^{5}$ As particularidades, além da pobreza, que distinguem as experiências vivenciadas pelas/pelos jovens em seu contexto social, podem ser observadas, por exemplo, no que tange a questões de gênero, raça/etnia, sexualidade, estética corporal, territorialidade, etc. (DAYRELL, 2003). Consideramos que, assim como a pobreza, essas são de extrema significância, entretanto, abordá-las extrapola o escopo desse trabalho.
} 
A natureza é o corpo inorgânico do homem, a saber, a natureza enquanto ela mesma não é o corpo humano. O home vive da natureza significa: a natureza é o seu corpo, com o qual ele tem de ficar num processo contínuo para não morrer. Que a vida física e mental do homem está interconectada com a natureza não tem outro sentido senão que a natureza está interconectada consigo mesma, pois o homem é uma parte da natureza (MARX, 2004, p. 84).

Por outro lado, mas sem negar ou subtrair aquela, a dimensão social diz respeito apenas ao gênero humano, e não à totalidade da natureza. Isto é, essa advém de processo de objetivação do ser pela sua interação com o mundo exterior, pela práxis social, tendo o trabalho como modelo, ou seja, da modificação do mundo natural e, consequentemente, de si mesmo, e poderá desenvolver a sua potência interior, possibilitada pela sua espécie (MARX, 2004). Isto é,

\begin{abstract}
O animal é imediatamente um com a sua atividade vital. Não se distingue dela. É ela. O homem faz da sua atividade vital mesma um objeto da sua vontade e da sua consciência. [...] Justamente, [e] só por isso, ele é um ser genérico. Ou ele somente é um ser consciente, isto é, a sua própria vida lhe é objeto, precisamente porque é um ser genérico. Eis por que a sua atividade é atividade livre (MARX, 2004, p. 84).
\end{abstract}

Nesse sentido, a essência social não está em si mesmo, mas fora de si. Logo, tem-se o mundo da cultura, em que as gerações primeiras repassam a seus descendentes a herança cultural anteriormente construída. Dessa forma, o homem possui em sua gênese a potência de se tornar um ser social, no entanto, é no processo de socialização que materializa, concretiza sua dimensão social, para além da natural, instintiva (MARX, 2004).

Assim, percebe-se que a dimensão biológica e a dimensão social influenciam mutuamente no desenvolvimento do ser social. No entanto, cabe acrescentar que, a humanidade, em sua posição de sujeito, tramita nessa dupla determinação como um ser interventivo, isto é, como um ser social histórico, que não apenas é determinado pelo contexto social em que se encontra, mas que também o determina com sua ação. $O$ que o situa na dialética da realidade, visto que ao mesmo tempo em que sua socialização, delineadas pela sua condição social, o permeiam, ele também reinventa e recria sua socialização dentre as possibilidades existentes (MARX, 2004). Portanto, diante disso, deve-se compreender a/o jovem como um ser social em processo de socialização. Visto que

[...] a socialização dos jovens pode ser compreendida como os processos por meio dos quais os sujeitos se apropriam do social, seus valores, normas e papéis, a partir de uma determinada posição e de uma representação das próprias necessidades e interesses, mediando continuamente entre diversas fontes, agências e mensagens que lhes são disponibilizadas (DAYRELL, 2005, p. 182).

Todavia, com a peculiaridade de que nesse momento da vida, a juventude, é iniciada a 
ampliação e ressignificação das esferas de interação social já presente em sua infância, como a família e a escola, seguida pela esfera do trabalho $^{6}$ e, como mostraremos, da produção cultural. Essas instâncias de socialização são totalidades que não se constituem de forma homogênea para as/os jovens, pois, como visto, tanto a formação desses ambientes, suas normas e rituais, como as interações vivenciadas no tempo/espaço, são particularizados em sua fundação e vivenciados de forma singular, a partir da condição de pobreza.

Desse modo, a socialização se constitui e resulta do processo educativo, pelo qual seres humanos constituem-se em seres sociais, como expõe Almeida (2018, p. 2):

A educação como dimensão da vida social possui um caráter ontológico, ou seja, constitutivo dos modos de existência humana, do ser social, da organização da vida em sociedade. [Logo] A família, as instituições religiosas, os movimentos associativos entre outras, ao lado da escola contribuem para a constituição do amplo e diversificado campo educacional.

Isto é, a educação se constitui enquanto processo socializador ampliado, que se dá na escola, mas, também, para além dessa. Além disso, salienta o autor, tais espaços não são homogêneos e imutável, logo, tendo visto que "[...] muitas dessas instituições tenham sofrido profundas transformações em suas funções educativas, particularmente a partir das necessidades de expansão do próprio capital [...]", faz-se necessário "[...] pensar os processos de mercantilização das relações sociais como uma necessidade da própria lógica de expansão do capital e, consequentemente, a educação como condição e resultado desse processo [...]" (ALMEIDA, 2018, p. 2).

A educação, portanto, consiste em processo complexo, que envolve diversos espaços, instituições e sujeitos, estando imersa nas particularidades da realidade social. O que significa afirmar que ela está mediada pelas relações próprias da sociedade capitalista, cuja prioridade é acumular e centralizar capital em detrimento do desenvolvimento humano (MARX, 2011b). Ou seja, ao pensar os espaços de socialização em que se dá o processo educativo, "requer não perder de vista a historicidade dessa dinâmica, evitando-se subverter o pensamento sobre a realidade aos limites impostos por uma de suas possibilidades históricas" (ALMEIDA, 2018, p. 2).

Acerca disso, Dayrell (2005) nos aponta que é recorrente, nas análises sobre a juventude, o indicativo de crise da esfera da família, da escola e do trabalho, no que tange ao desenvolvimento de seu papel de orientação e de repasse de valores para as novas gerações.

\footnotetext{
${ }^{6}$ Sabe-se que o trabalho remunerado, até mesmo análogo ao escravo, é presente na realidade das crianças da classe trabalhadora, principalmente daquelas em situação de pobreza. Entretanto, essa variável demanda uma abordagem além daquela prevista como objetivo desse ensaio. Para maior aprofundamento acerca do trabalho infantil ver Serviço Social \& Sociedade, ano XXVI, n. 83, Cortez, São Paulo, 2005.
} 
Entretanto, é importante nos perguntar se isso ocorre, porque ocorre? Isto é, não se pode negar a dimensão socializadora destes espaços, pura e simplesmente, visto que a sociedade atual tende a se organizar em torno da família, da escola e do trabalho, mas sim de problematizar e relacionar as particularidades desses em relação as/aos jovens pobres.

Acerca disso, no que tange à família, cabe destacar que não se trata de considerar a existência de uma "crise moral" que ocasiona o desmembramento de "uma determinada estrutura, tomada como ideal (casal com seus filhos) e com papéis pré-definidos" (MIOTO, 2010, p. 168). Ao contrário, como afirma Mioto (2010, p. 167-168):

\begin{abstract}
A família, nas suas mais diversas configurações constitui-se como um espaço altamente complexo. É construída e reconstruída histórica e cotidianamente, através das relações e negociações que estabelece entre seus membros, entre seus membros e outras esferas da sociedade e entre ela e outras esferas da sociedade, tais como Estado, trabalho e mercado. Reconhece-se também que além de sua capacidade de produção de subjetividades, ela também é uma unidade de cuidado e de redistribuição interna de recursos.
\end{abstract}

Isto é, a família é uma estrutura social que vai além das relações entre indivíduos circunscritos em seu domicílio mediante uma rede social primária. Logo, parte-se aqui do entendimento de que a família se constitui de estrutura de constante movimento e em profunda conexão com os demais locus da sociedade, sendo capaz de transgredir/superar, mas também, de reafirmar/preservar estruturas participativas e decisórias que desabonam a/o jovem. Nesse sentido, ao observarmos as particularidades contemporâneas da juventude pobre, destaca-se a contribuição de Carrano (2012, p. 92), quando afirma que:

Contudo, ainda que o campo da liberdade tenha se alargado, a dependência dos jovens, especialmente a econômica, se constitui em entrave real para a conquista da autonomia. Esta aqui entendida como processo de conclusão do processo de individuação, ou seja, do jovem que passa a ser sujeito do próprio destino. Ou ainda, como diriam nossos pais, "donos do próprio nariz".

Portanto, a família, enquanto locus de socialização das juventudes, reproduz, hegemonicamente, relações hierárquicas, discriminatórias e antidemocráticas, em que o poder de "voz e voto" restringem-se aos adultos provedores. Isto é, Carrano (2012, p. 90) aponta que "O que se discute aqui, então, está relacionado com a maior ou menor abertura para a partilha do poder de decisão. $E$ isso é algo que está na base histórica de desigualdade dos relacionamentos geracionais entre jovens e adultos".

Apesar da hierarquia familiar ser motivada pelo fator cronológico e comportamental juvenil, logo, fazendo-se presente nos diferentes segmentos sociais, destaca-se que essa apresenta particularidades no bojo das famílias pobres. Isso porque, como afirma Carrano (2012), se a 
autonomia da/do jovem está relacionada ao processo de independência financeira desses, tal condição encontra maior dificuldade de se materializar entre a classe trabalhadora. Isso porque, coerente com o que afirma Mioto (2010), a família é constituída, além das relações entre seus membros, pelas relações sociais capitalista, na qual se inclui o alargamento do desemprego e a predominância de baixo salários que acometem a classe trabalhadora em âmbito global.

Também imerso nessa complexidade, a escola é, a priori, conceituada como o espaço institucional de educação mais tradicional, cujo objetivo central tange a formação da cidadania e da profissionalização e se dá no bojo das relações entre estudantes, educadores, família e comunidade. Nela tem predominado a compreensão de que "[...] a juventude vem representando um período de espera formativa em função do objetivo da preparação para a entrada na vida adulta" (CARRANO, 2012, p. 84), o que tem culminado na predominância de uma pedagogia voltada à formação para o mercado de trabalho, além da ausência de reconhecimento das particularidades expressas na vida das/dos jovens.

Apesar de estar presente nos diversos segmentos da juventude, destaca-se que a escola - espaço, objetivo e relações - não se trata de sinônimo de educação ${ }^{7}$, mas sim um locus onde essa se dá. Nesse ponto e vista, a escola, assim como a família, também é constituída pelos sujeitos - estudantes e educadores - e tangenciada pelas relações sociais. Logo se trata de espaço de socialização, que se constitui, de forma diferenciada, para a juventude pobre, e é, cotidianamente, permeado pelas expressões da "questão social", como expõe Almeida (2018, p. 3):

\begin{abstract}
A escola [...] se vê atravessada por uma série de fenômenos que, mesmo não sendo novos ou estranhos ao universo da educação escolarizada, hoje se manifestam de forma muito mais intensa e complexa: a juventude e seus processos de afirmação e reconhecimento enquanto categoria social, exacerbadamente, mediado pelo consumo; a ampliação das modalidades e a precoce utilização das drogas pelos alunos; a invasão da cultura e da força do narcotráfico; a pulverização das estratégias de sobrevivência das famílias nos programas sociais; a perda de atrativo social da escola como possibilidade de ascensão social e econômica; a negação da profissionalização da assistência no campo educacional com a expansão do voluntariado; a gravidez na adolescência tomando o formato de problema de saúde pública e a precarização das condições de trabalho docentes são algumas das muitas expressões da questão social.
\end{abstract}

Esses fenômenos, que permeiam o cotidiano escolar, são alvo do conjunto de ações cuja pedagogia, salvo algumas exceções, pode ser considerada "[...] um exemplo típico de protagonismo juvenil orientado para o ajustamento de condutas de jovens populares e que, em última instância, camufla contradições, naturaliza precariedades em territórios de pobreza e inibe

7 A educação, como instância da vida social, trata-se de processo muito mais abrangente, como abordamos anteriormente, conforme Almeida (2018). 
conflitos relacionados com a busca de direitos da juventude" (CARRANO, 2012, p. 89) ${ }^{8}$. Isto é, trata-se de ações que tem como finalidade o controle social e o ajustamento da/do jovem, além de ofertar aquilo que se julga ser a necessidade desses sujeitos, sem a preocupação do diálogo e da escuta de suas demandas.

No que tange à esfera do trabalho ${ }^{9}$, no processo de socialização das/dos jovens, destacase a representatividade desse espaço. Acerca disso, Zaluar (2000) nos aponta, em abordagem histórica, que a ética do trabalho culminou na ética do provimento da família pobre, em que o responsável familiar dedica a sua vida ao trabalho, movido pela necessidade de sobrevivência do seu grupo. Entretanto, posteriormente, diante das poucas oportunidades de emprego e baixa remuneração, há uma mudança na representatividade da atividade laboral no bojo da juventude pobre, que culmina na desconstrução da ética do trabalho e do provimento da família. Isto é, para a autora, as precárias condições de trabalho figuram como uma das razões da revolta de parcela das/dos jovens pobres, visto que ao passo que negam a normalidade dessa situação, direcionam seus esforços a atividades laborais ilícitas, mas de grande rendimento econômico.

Por outro lado, as/os que permanecem em trabalhos legalizados, seja ele formal ou informal, indagam-se acerca da baixa adesão às organizações sindicais. Acerca disso, Carrano (2012, p. 94) expõe que predomina nesse público maior engajamento em processos organizados em torno de uma "causa", com processos decisórios ampliados e cujos objetivos não sejam porvindouros, constituindo-se, em "um dos maiores entraves para as instituições de base de participação clássica”. Essa reflexão permite ao autor ratificar a pertinência desses espaços, embora destaque que

É preciso indagar como se reinventam as tradições militantes e como são questionados os antigos modelos de participação institucional. Quem são os novos herdeiros dessas práticas? Como as velhas e novas formas interagem e compõem novas sínteses políticas, convivem em que termos e quais são os focos de continuidade e tensão? De que formas os espaços clássicos de participação absorvem ou não os vetores que chegaram através dos diferentes coletivos de identidade, tais como negros, mulheres, LGBT, deficientes? (CARRANO, 2012, p. 93).

Diante desses espaços de socialização tradicional, família-escola-trabalho, a/o jovem reflete acerca de sua percepção e atuação nos espaços em que vivencia, e passa a demandar novos interesses e expectativas a estes, que, se percebidas, pois na maioria das vezes são

\footnotetext{
${ }^{8}$ Acerca disso, Carrano (2012) relata que a maioria das ações nesse campo trata-se de palestras de conscientização sobre o uso de drogas e a gravidez na adolescência, isto é, expressam pouco estímulo de participação e muito foco na passagem de informação.

${ }^{9}$ Cabe ainda nesse quesito, esclarecer que o e conceito de trabalho é aqui utilizado para se referir ao mercado de trabalho, esfera de socialização no mesmo patamar da família e da escola, logo diferindo do sentido da categoria trabalho, fundamento ontológico do ser social, como exposto em Marx (2004).
} 
ignoradas, provocando sua evasão daquele ritual socializador. Como explicita Dayrell (2007, p. 1114),

\begin{abstract}
Tais mutações interferem diretamente nas instituições tradicionalmente responsáveis pela socialização das novas gerações, como a família ou a escola, apontando para a existência de novos processos. Podemos afirmar que, na sociedade contemporânea, os atores sociais não são totalmente socializados a partir das orientações das instituições, nem a sua identidade é construída apenas nos marcos das categorias do sistema.
\end{abstract}

Percebemos, desse modo, que as instituições encontram-se instrumentalmente defasadas diante das novas exigências da juventude. O que, frequentemente, reflete-se em ação arbitrária e autoritária, ou mesmo despreocupada e descompromissada, diante do público juvenil, cujo objetivo central é adequá-lo às normativas institucionais e sociais a qualquer custo. Ou seja, como afirma Pais (1990, p. 141)

[...] a juventude tem sido encarada como uma fase da vida marcada por uma certa instabilidade associada a determinados «problemas sociais». Se os jovens não se esforçam por contornar esses «problemas», correm mesmo riscos de serem apelidados de «irresponsáveis» ou «desinteressados». Um adulto é «responsável», diz-se, porque responde a um conjunto determinado de responsabilidades: de tipo ocupacional (trabalho fixo e remunerado); conjugal ou familiar (encargos com filhos, por exemplo) ou habitacional (despesas de habitação e aprovisionamento). A partir do momento em que vão contraindo estas responsabilidades, os jovens vão adquirindo o estatuto de adultos.

Esse entendimento traduz a percepção da juventude no marco do eixo geracional, em que é definida apenas como fase cronológica da vida, cujos comportamentos precisam ser adequados à preparação da fase adulta. Entretanto, embora seja predominantemente nos espaços de socialização tradicional de amplos segmentos juvenis, destaca-se que há uma particularidade em relação as/aos jovens pobres no que tange a ação disciplinadora direcionada à classe trabalhadora. Isto é, o jovem pobre, ao negar a naturalidade normativa direcionada a si, não questiona apenas a limitação comportamental que lhe é atribuída. Além disso, recusa os "lugares" e as "funções sociais" determinados à sua classe originária, principalmente ao segmento empobrecido em que se insere. Assim, tende a buscar outros espaços em que possa concretizar sua singularidade e realizar-se, sendo isto nada mais que sua potencialidade enquanto ser social. Ou seja, buscará se reconhecer e ser reconhecida/o em suas atividades socializadoras, e, para tal, tende a ir além, a criar e/ou reinventar os espaços de socialização.

Esse processo de positivação pode ser observado na constituição dos grupos de produção cultural. Cabe destacar que esse também está em conexão com as relações sociais contemporâneas, estando sujeito ao processo de positivação e negação da individuação; logo, não se pretende ignorar a dimensão socializadora dos espaços tradicionais, nem mesmo 
enaltecer este último. O que se busca, é observar esse locus, que longe de ser novo, ainda carece de maior adensamento sobre suas particularidades contemporâneas, principalmente, no que tange a sua constituição enquanto locus de ampliação da rede de socialização tradicional, família-escola-trabalho.

Acerca disso, portanto, observa-se que a/o jovem, diante da impossibilidade de objetivarse de forma autônoma, vê-se em conflito com os demais sujeitos em torno da gama de ideias e de valores a que se expõe no processo de conhecimento e ocupação de espaços em seu contexto social, e que nem sempre são convergentes ou similares. Isto é, na juventude, passa a ter maior percepção das contradições que permeiam o meio em que convive e das diversas formas que a sociedade produz os indivíduos (DAYRELL, 2007).

Além da ampliação da percepção das contradições, o fator de alargamento de experiência também incita a/o jovem a outras duas formas diferentes: traz a necessidade de se diferenciar e de se afirmar no seu meio social, processo que influencia a busca pela formação de grupos, de pares (DAYRELL, 2005).

Nesse bojo, a inserção das/dos jovens em grupos de produção cultural pode ser visto como "[...] espaços que até então eram exclusivos da família, do trabalho e da escola na construção ou formação das identidades das novas gerações" (SAID, 2010, p. 2). Ou seja, corroboramos que as juventudes não insurgem com e nem possuem prontas as ideações acerca das normativas da convivência social e da produção da vida material, mas que estas são geridas e formuladas em espaços de socialização coletiva.

Esse processo de negação/afirmação, portanto, forja a constituição das/dos jovens, que buscam objetivar tais ideações pelos grupos culturais, por exemplo. Esses consistem espaço de socialização permeado de confrontos de representações acerca da vida social, isto é, um locus de trocas entre jovens enquanto sujeitos fecundos de contestação e construção.

A produção cultural, portanto, representa espaço privilegiado para produção de identidades coletivas e individuais, por ser espaço de produção e reprodução de práticas sociais. Sendo assim, trata-se de local fecundo de possibilidade para a construção de objetivações como a música, a poesia, o teatro, a pintura, etc. Isto é, essas podem tanto configurar-se de forma desantropomorfizadora ou antropomorfizadora, sendo, respectivamente, como afirma Lukács (1996, p. 226-227), "ou se parte da realidade objetiva, levando para consciência seus conteúdos, suas categorias, etc., ou tem lugar uma projeção de dentro para fora, do homem para natureza".

Nesse sentido, a produção cultural juvenil, como arte, consiste na objetivação de sua subjetividade humana, cujo produtor/receptor tem a possibilidade de sistematizar/entender 0 
movimento contraditório e mediado da realidade social historicizada. Concorda-se com o autor, quando este afirma que "foram tantas as obras de arte que nos serviram como veículo de informação, sendo continuamente estudadas e explicadas pelos especialistas porque representam documentos históricos extraordinariamente importantes de épocas passadas", e, por isso, acredita que nessas obras “[...] é revivido e feito presente precisamente o próprio passado, não o passado como sendo a vida anterior pessoal de cada indivíduo, mas sim como sua vida anterior enquanto pertencente $\underline{\underline{z}}$ À humanidade (LUKÁCS, 1978, p. 288-289).

Sendo assim, ao ocupar o espaço de produção cultural, as/os jovens se veem diante da possibilidade de ampliar sua condição de sujeito ativo na construção da vida coletiva. Isso porque, como afirma Lukács (1978, p. 291),

\begin{abstract}
Ele [o sujeito] experimenta realidades que, de outro modo, na plenitude oferecida pela época, ser-lhes-iam inacessíveis; suas concepções sobre o homem, sobre suas possibilidades reais positivas ou negativas, ampliam-se em proporções inesperadas; mundos que lhe são distantes no espaço e no tempo, na história e nas relações de classe, revelam-se a ele na dialética interna daquelas forças cujo jogo exterior lhe oferece a experiência de algo que lhe é bastante estranho, mas que ao mesmo tempo pode ser posto em relação com sua própria vida pessoal, com a sua própria intimidade.
\end{abstract}

Portanto, a arte, como construção estética, tem o potencial de ser o meio pelo qual as/os jovens atuam no mundo e refletem sobre seu lugar. Movimento que permite, ao mesmo tempo, que o espaço de produção cultural, em seus diversos grupos, possa ser constituído pela contestação e proposição da realidade social.

Diante da potência desantropomorfizadora da arte, um exemplo a ser observado no que tange aos grupos de produção cultural como espaço de socialização da juventude pobre, na contemporaneidade, é o grupo cultural Slam Resistência ${ }^{10}$, que consiste na apresentação vocal de poesia autoral, spoken word, sem a utilização de qualquer outro recurso, em no máximo três minutos, sendo precedidas do mote: “Sabotagem, Sem Massagem na Mensagem!". Depois da apresentação, ocorre a avaliação dos jurados, que são escolhidos a cada seção, entre os presentes, esses atribuem a nota de zero a dez e, ao final, o poeta com maior média vence (SLAM RESISTÊNCIA, 2018).

Cabe destacar que o surgimento do slam é contextualizado no final da década de 1950 e início de 1960, nos Estados Unidos, e remete à criação do spoken word, que significa "palavra falada" e trata de "uma performance na qual as pessoas recitam textos". Estes, entretanto, são os únicos consensos a seu respeito. Isso porque, por um lado, atribui-se a formulação do spoken

\footnotetext{
10 Para conhecer o Slam Resistência acesse https://www.facebook.com/slamresistencia/; além de presencialmente a primeira segunda-feira de cada mês na Praça Rosevelt, no centro de São Paulo-SP.
} 
word à Geração Beat, que visava a popularização da leitura pública de poesia, levando-a para além dos muros das universidades, bibliotecas e instituições. Por outro lado, têm-se a crítica de que os "beats" criaram uma geração de hipsters ${ }^{11}$, e atribui-se a concepção aos movimentos populares que lutaram pelos direitos civis e contra o racismo (ZAP, 2018).

Apesar disso, o spoken word se popularizou na década de 1980 e 1990 por causa da criação do poetry slam ${ }^{12}$, nos anos 1980, por Marc Kelly Smith, em Chicago. Essa inovação renovou e difundiu mundialmente ${ }^{13}$ a poesia oral, sendo entendido como "Um slam de poesia é um evento de poesia performática atual que geralmente culmina em uma batalha figurativa entre os slammers (poetas de slam)" (ZAP, 2018).

\begin{abstract}
Os primórdios do slam como é conhecido hoje remontam a o clube de jazz "Get Me High" em Chicago, onde nas noites de segunda-feira Marc Kelly Smith apresentava uma noite experimental de poesia. No dia 20 de novembro de 1986, no "Green Mill Jazz Club" estrearia a noite onde pela primeira vez o termo "poetry slam" foi usado para denominar as noites de poesia performática e mais tarde as competições de poesia (ZAP, 2018).
\end{abstract}

Somente na década de 2000 tem sua expressão iniciada no Brasil, e "O primeiro campeonato brasileiro foi o ZAP $^{14}$ (Zona Autônoma da Palavra), no Núcleo Bartolomeu de Depoimentos, coletivo de Teatro e Hip Hop, criado pela Roberta Estrela D'Alva, atriz, apresentadora (atualmente no programa Manos e Minas da TV Cultura) e diretora musical". Desde então, o slam cresce em todo o país, com maior incidência na cidade de São Paulo, e realiza-se ao final de cada ano o Slam $B R$, competição nacional em que os ganhadores estaduais competem entre si elegendo um representante nacional ${ }^{15}$ para participar na Copa do Mundo da França de Poesia Falada (ILLY, 2018).

O Slam Resistência, em particular, define sua própria constituição "na sintonia dos protestos, dos movimentos sociais e do enfrentamento político ativo em defesas culturais/sociais, sócio-ambientais e contra truculência do estado para com os manifestantes!". Isto é, se propõe a ser um espaço de construção de reflexões a partir da realidade objetiva, a fim de entendê-la e propor ações a partir dela. Como expresso no trecho:

\footnotetext{
11 Termo que representa uma subcultura da classe média urbana que coexiste com a cultura dominante.

12 Nos Estados Unidos "O slam se tornou nacional, com campeonatos (o primeiro National Poetry Slam acontece em 1990), poetas 'slammers' gravando discos, programas de tv (como o 'Def Poetry Jam' da HBO apresentado por Mos Def), filmes ('Slam', de 1997 com Saul Williams vencedor da camera d'or em Cannes e do grande prêmio do júri no Sundance Festival) e popularizou-se espalhando pelo mundo inteiro" (ZAP, 2018).

13 "Estima-se hoje que existam pelo menos 500 comunidades de Slam em países como Irlanda, Inglaterra, Austrália, Zimbabwe, Madagascar, Israel, Singapura, Polônia, Itália e até mesmo no Pólo Sul, no Hawaí e agora no Brasil, sendo que as maiores comunidades fora dos EUA estão na França e na Alemanha" (ZAP, 2018).

${ }^{14}$ Sobre o ZAP ver http://zapslam.blogspot.com.

15 "Na final do campeonato brasileiro de 2016 a vencedora foi a poeta Luz Ribeiro, primeira mulher negra a ganhar a competição. Em Paris, Luz ficou em nono lugar" (ILLY, 2018).
} 
Através da participação e competição de spoken world, campeonato de poesias faladas, no Slam da Guilhermina ${ }^{16}$, o primeiro slam de rua do Brasil, segundo slam do país, Del Chaves (idealizador), junto aos protestos que tomaram as ruas e 2013/2014, sentiu o chamado pra começar esta nova modalidade de intervenções poéticas num local de reuniões de mov. sociais com intuito de potencializar tanto os protestos quanto os poetas/poetizas desta cena emergente! (SLAM RESISTENCIA, 2018).

Ademais, se propõe a "pra além das Poesias discutir formas de Intervenções Socioculturais no meio da babylônia de concreto, o Slam Resistência será na Roosevelt ao lado do nosso querido Parque Augusta o qual queremos usufruir!" (SLAM RESISTÊNCIA, 2018). Desse modo, percebe-se o potencial desantropomorfizador do Slam Resistência, enquanto espaço de socialização das/dos jovens pobres, que pode ser observado, por exemplo, na visão de mundo, nos temas abordados e na origem dos participantes.

Assim, tem-se as declarações de Charles Monteiro de Jesus, um dos organizadores, que esclarece acerca da fundação do Slam Resistência, que ocorreu em 2014, originado a partir das jornadas de junho de $2013^{17}$.

Começou em reuniões que aconteciam na Roosevelt, chamadas Quintas de Resistência. Essas reuniões aconteciam entre movimentos sociais e advogados ativistas. Esses grupos debatiam e falavam muito sobre violência policial contra manifestantes. Em 2013, aconteceram manifestações em diversos lugares do país (VALERY, 2018).

Além dessa expressa ligação com os conflitos sociais em sua emergência, percebe-se a continuidade da conexão com o movimento da realidade nacional, quando o organizador menciona a conjuntura do país após o impeachment de Dilma Rousseff:

Estamos preocupados, porque parece que parte da população está anestesiada. Está em silêncio. Tem uma música do Chico que ele diz que 'esse silêncio todo me atordoa'. Me incomoda muito porque parece que está tudo bem, mas não está. Aumentou a fome, aumentou o número de pessoas em situação de rua, a miséria. Nos bairros mais afastados também tem esse reflexo (VALERY, 2018).

Desse modo, acerca dos temas abordados nas competições de spoken word, que chega

\footnotetext{
${ }^{16}$ Sobre o Slam da Guilhermina ver:

https://www.youtube.com/channel/UCm3LjEJzzPOh5yxUGbGXEnA
}

17 As "jornadas de junho" referem-se ao conjunto de manifestações populares que se deram no Brasil no ano de 2013, inicialmente, expressando a contestação do aumento da passagem do transporte público rodoviário municipal - também mencionadas como "manifestações dos 20 centavos" - que sofreu forte repressão policial. Posteriormente, além da luta pela redução da tarifa e da repressão policial, houve uma ampliação das reivindicações e do quantitativo de manifestantes (que ultrapassou a um milhão em todo o país) que problematizam os gastos públicos com grandes empreendimentos esportivos (copa do mundo de futebol e olimpíadas), bem como a corrupção, em detrimento de serviços públicos e Da qualidade de vida da população. Como resultado, tem-se, por exemplo, a aprovação pelo Congresso Nacional da corrupção como crime hediondo e a revogação do aumento das tarifas em várias cidades. 
a reunir cerca de 700 pessoas, o organizador atribui-Ihes a pertinência do Slam Resistência, em que "Ultimamente os temas políticos estão bem fortes. Coisas do cotidiano. Tem muita coisa sobre feminismo, racismo, machismo. Estes são temas recorrentes" (VALERY, 2018).

Isso porque, a origem dos participantes é da classe que sofre com a degradação das condições de vida, pois, como Charles esclarece, "A maioria deles vem da periferia. Como estamos no centro, fica fácil para convergir". O que, na sua opinião, significa que "Se as pessoas estão vindo de vários lugares é porque de alguma forma o que é dito ali é importante. [...] Isso mostra que algo de positivo está sendo dito". Para ele, portanto, "A poesia tem ajudado muitas pessoas, aquelas que sofrem caladas. Ela as tira da violência do cotidiano. Percebemos isso a cada dia com pessoas que passam por lá" (VALERY, 2018). O que é ratificado por Gabi Albuquerque, uma das compositoras de slam:

Quando você tem movimentos assim, você pega pessoas marginalizadas pela sociedade e pela mídia e fala: 'O que você tem pra falar pra gente?'. Tem uma relevância histórica muito grande, porque nos livros você só encontra o que é contado pelo vencedor. O slam é uma oportunidade para quem está apanhando todo dia falar (VALERY, 2018).

Diante o exposto, pode-se perceber como os grupos culturais desempenham em si o processo de socialização das/dos jovens pobres, assim como a família, a escola e o trabalho. Apesar de estar imerso nas contradições próprias da sociabilidade capitalista, também apresenta potencial concreto de experiências de gestão democrática e de construção de reflexões desantropomorfizadoras da realidade social.

\section{ALGUMAS CONSIDERAÇÕES}

Assim, pretende-se ter elencado alguns elementos para a análise do processo de socialização das/dos jovens. Visto que, pelos resultados da pesquisa a que se remete esse esforço expositivo, buscamos contribuir para o debate acerca das políticas sociais voltadas para as juventudes e, ainda, subsidiar outros estudos que busquem conhecer as juventudes viventes. Ou seja, ao desenvolvermos essa pesquisa, buscamos compreender de que maneira a dimensão cultural e política do "produzir e reproduzir em comunidade" interfere na percepção juvenil acerca da realidade social, visto que a identidade das/dos jovens refere-se À construção no bojo dos antagonismos culturais e políticos.

Entende-se que esses antagonismos, manifestos nos espaços tradicionais família-escolatrabalho, são próprios do antagonismo de classes. Uma vez que os territórios são construídos, tradicionalmente, a partir da implantação e expansão dos meios de reprodução do capital e da 
força de trabalho.

Por outro lado, a produção cultural, como esfera de socialização das juventudes, não compõe-se como locus ideal e neutro, tão certo que também está permeado pelas contraditórias relações sociais contemporâneas. Entretanto, apesar disso, expressa-se como lugar de potência, tanto do ponto de vista da forma - autogestado pelas/pelos jovens - como de seu conteúdo autonomia de criação de suas ideações sobre a realidade social, bem como projeções dessa realidade para a sociedade.

\section{REFERÊNCIAS}

ALMEIDA, Nei Luiz Teixeira de. O Serviço Social na Educação: novas perspectiva sócioocupacionais. Disponível em:

http://necad.paginas.ufsc.br/files/2012/07/O Servico Social na Educacao perspectivas socio ocupacionais1.pdf. Acesso em: 27 maio 2018. Google

BRASIL. LEI N. 12.852, de 05 de agosto de 2013. Institui o Estatuto da Juventude e dispõe sobre os direitos dos jovens, os princípios e diretrizes das políticas públicas de juventude e o Sistema Nacional de Juventude - SINAJUVE.

CARRANO, Paulo. A participação social e política de jovens no Brasil: considerações sobre estudos recentes. O Social em Questão, ano xv, n. 27, p. 83-100, 2012. Google

DAYRELL, Juarez. O jovem como sujeito social. Revista Brasileira de Educação, Rio de Janeiro, n. 24, set./dez. 2003. Google

DAYRELL, Juarez. A música entra em cena: o rap e o funk na socialização da juventude. Belo Horizonte: Editora UFMG, 2005. Google

DAYRELL, Juarez. A escola "faz" as juventudes? Reflexões em torno da socialização juvenil. Educação e Sociedade, Campinas, v. 28, n. 100 - Especial, p. 1105-1128, out. 2007. Google

GIL, Antonio Carlos. Como elaborar projetos de pesquisa. São Paulo: Editora Atlas, 2002. Google

ILLY, Katy. Um pouco sobre Slam, Spoken Word, Poesia Marginal. Las Pretas: cultura pop marginal. 04 set. 2017. Disponível em: http://laspretas.com.br/slam-spoken-word-e-poesiamarginal/. Acesso em: 30 maio 2018.

LIMA, Telma Cristiane Sasso de; MIOTO, Regina Célia Tamaso. Procedimentos metodológicos na construção do conhecimento científico: a pesquisa bibliográfica. Katálysis, Florianópolis, v. 10, n. esp. 2007. Google

LUKÁCS, Gyorg. Estético: Tomos I - La Peculiaridad De Lo Estetico. Trad. Manuel Sacristán. Barcelona: Grijalbo, 1966.

LUKÁCS, Gyorg. As bases ontológicas do pensamento e da atividade do homem. Trad. Carlos Nelson Coutinho. In: LUKÁCS, Gyorg. Temas de Ciências Humanas. São Paulo: Ciências 
Humanas, 1978.

MARX, Karl. Os manuscritos econômico-filosóficos. São Paulo: Boitempo, 2004.

MARX, Karl. O método da Economia Política. In: MARX, K. Contribuição à crítica da economia política. Trad. e Intr. Florestan Fernandes. 2. ed. São Paulo: Expressão Popular, 2011a.

MARX, Karl. O capital: crítica da economia política. Livro I, vol. II. 24를 ed. Rio de Janeiro: Ed. Civilização Brasileira, 2011b.

MIOTTO, Regina Célia. Família, trabalho com famílias e Serviço Social. Serviço Social em Revista, Londrina, v.12, n.2, p. 163-176, jan/jun. 2010.

NETTO, José Paulo. Capitalismo Monopolista e Serviço Social. 7. ed. São Paulo: Cortez, 2009. Google

NETTO, José Paulo. Introdução ao estudo do método em Marx. São Paulo: Expressão Popular, 2011.

PAIS, José Machado. A construção sociológica da juventude - alguns contributos. Análise Social, v. 25, n.105/106, p. 139-165, 1990. Google

SAID, Camila do Carmo. Os grupos musicais juvenis e a participação das jovens mulheres. Disponível em:

http://www.fazendogenero.ufsc.br/7/artigos/C/Camila do Carmo Said 01.pdf. Acesso em 16 maio 2010.

SARTI, Cyntia. A família como espelho: um estudo sobre a moral dos pobres. Campinas: Autores Associados, 2005.

SILVA, Maria Ozanira da Silva e. Pobreza, desigualdade e políticas públicas: caracterizando e problematizando a realidade brasileira. Katálysis, Florianópolis, Universidade Federal de Santa Catarina, v. 13, n. 2, p. 155-163. jul./dez. 2010. Google

SLAM RESISTÊNCIA. Página na rede social facebook. Disponível em: https://www.facebook.com/pg/slamresistencia/about/?ref=page internal. Acesso em: 30 maio 2018.

SPOSITO, Marília Pontes; CARRANO, Paulo César Rodrigues. Juventude e Políticas públicas no Brasil. Revista Brasileira de Educação, n. 24, dez. 2003. Google

SOUSA, Janice Tirelli Pontes de. Reinvenções da Utopia: a militância política de jovens nos anos 90. São Paulo: Hacker Editores, 1999. Google

VALERY, Gabriel. Slam Resistência: A poesia e a voz de quem sempre sofreu calado. Revista do Brasil, n. 381, 10 mar. 2018. Disponível em:

http://www.redebrasilatual.com.br/revistas/138/slam-resistencia-a-poesia-e-a-voz-de-quemsempre-sofreu-calado. Acesso em 30 maio 2018.

ZALUAR, Alba. A máquina e a revolta: as organizações populares e o significado da pobreza. 
São Paulo: Brasiliense, 2000.

ZAP. Zona Autônoma da palavra. Site. Disponível em:

http://zapslam.blogspot.com/search/label/SLAM. Acesso em: 10 jun. 2018. 